International Journal of Trend in Scientific Research and Development (IJTSRD)

Volume: 3 | Issue: 2 | Jan-Feb 2019 Available Online: www.ijtsrd.com e-ISSN: 2456 - 6470

\title{
Innovative Teaching Strategies in Mathematics and Statistics
}

\author{
Kalpana Abhay Ghatpande
}

Assistant Professor, Department of Management Tilak Maharashra Vidyapeeth, Pune, Maharashtra, India

\begin{abstract}
During II world war the Military Officials used the system of planning the war material for the future days, that was actually system of Mathematical Modeling. The idea of Statistical Methods. The impact of this has started to change course content and structure, in both introductory and advanced courses for statisticians as scientists and academicians. So for future directions in the teaching and learning of statistics must take into account new innovative pedagogical instructions, educational technologies and the abundance of Web resources that are now available. With the Statistics, Mathematics is very much important Subject to study but much hard to learn and study. This paper gives the new solution to this problem. And currently identified challenges in the teaching and learning of statistics \& Mathematics of useful strategies and innovations for developing research-based statistics courses in the context of recommendations for reforms, outlining the place of information technology within this framework. \& a review of the literature on the topic of statistics \& Mathematics education and gives instructors a set of guidelines for generating new and effective teaching material.
\end{abstract}

KEYWORDS: Practical examples, use of Statistical tools, Interpretation of the tools, LPP, Graphs, Collection of Data

\section{INTRODUCTION}

$\mathrm{M}$ - for Mathematics

$\mathrm{M}$ - for Mother

We are very very close to our mother because our mother know us before and after of our life starts so is Mathematics. There is some conflate between ancient and modern studies. But there must be something which start with Pythagoras and will not end with Einstein, but is the oldest and the youngest. The Embryo is the basic single cell for the birth of human, in subsequent time span divides with the Mathematical rules as the first 2 parts and then $2^{n}$. But now

there is a trend in the students to say ,"I heat Mathematics ,it's very difficult to study and no use in life."

So teachers has to use many more different padagoes, ideas ,methods to make the teaching interesting and simple but useful like they want. To get the adequate response from the students, have to teach the subject with some audio-video methods like slides presentation, the creating good and light healthy environment to maintain the quality in teaching learning methods. The computational knowledge of the subject but is also concerned with the selection of the mathematical content and communication leading to its understanding and application. Teaching and learning mathematics involves complexities have to simplify if certain rules are followed. The appearance and quality of instructional material, like study Materials, different notes Question paper solution books the presentation of content, the pedagogic skills of the teacher, the learning environment, the motivation of the students are all important and must be kept in view in any effort to ensure quality in teachinglearning of mathematics. Now a days Mathematics playing roll in many different fields like Computer Science, Engineering, Valuation, Physiotherapy, Medicine, digital encryption, communication ,Management technology, modeling real life phenomena, predicting disasters, organization of enterprises, in business profit and loss and transport etc. It would be impossible to tackle any of the problems associated with mathematics education. So there must be the very simple but useful changes in the syllabus.
And each one of them will have been shaped by mathematics education. The word statistics regarded as the sciences of statecraft in ancient time it's used for the keeping records for the state administration s. Also the political parties used it. The records of land, agricultural activities health and wealth of the society. First time the statistical record was maintained by, Land \& Revenue Minister TORDAMAL of Akbar (in 1556-1605 A.D.) .After that in 16ooth century it was used for collection of data of the stars \& planets for prediction of the weather climate of the particular areas. In 17th century Captain John Grant of London introduce new phenomenon to use the statistics for the Medical field ,Social sciences ,Management, shares Business trends profit \& loss etc. and called as vital statistics. The life insurance company used it for preparing Mortality table \& calculations of expectations of life at different ages and groups. William Petty wrote a book,' 'Essay on Political Arithmetic (old name of Statistics).

\section{Objectives}

In this paper, efforts to discuss innovations and innovative practices in teaching mathematics at the undergraduate level, under teaching methods, strategies and pedagogic resources have been made. The process of innovation is generally described as consisting of three essential steps, starting with the conception of an idea, which is then proposed and is finally adopted. Though many ideas have been conceived to bring about change in the teaching of Mathematics, it is yet to be proposed and adopted. So, the innovations discussed may not be new in terms of the idea but is new in terms of practice. To collect the data on the current subject and to analyses it and write the proper interpretation with help of the use of Statistical tools.

1. To teach the most difficult subject with interesting ways.

a. 2. To make the subject more and more interesting and interpretative.

2. To make the students more techno savvy.

3. To get more positive response the from the students to attaind the lectures.

4. Use of computer and the soft wears to solve the numerical. 
Methods -Secondary data is use for the conclusions. The literature review of the available research papers on the subject.( Journal of Statistics Education ISSN: (Print) 10691898 (Online) Journal homepage: http://amstat.tandfonline.com/loi/ujse20

Statistical Education in the 21st Century: A Review of Challenges, Teaching Innovations and Strategies for Reform Svetlana Tishkovskaya \& Gillian A. Lancaster) . Not generated any formula but use the Statistical tools formulas, the method to improve the response to the study of Statistics and Mathematics in each and every field like Business, Computer Science, Physiotherapy, Nursing, Government Departments and all possible services. Method is a style of presentation of content in classroom. The following are the innovative methods that can be used to make teachinglearning process of Mathematics\& Statistics effective. I n general Mathematics is use to teach with Mathematical Induction Method. Induction method is use to prove from specific examples to generalization.In classrooms, usually instructions start with the abstract concepts which are beyond the understanding of the students. Formulas, theorems, examples, graphs results are derived, proved and used. So if teacher explain with specific examples, formula, the symbols and variables in the formula, how to decide the table to draw and put the values in the table, how to calculate the values in the columns and rows \& then move to generalizations and abstract things. Then teacher again needs to show how generalization can be derived and it holds true through specific examples. For example -To calculate the central tendency \&Measures of Desperation, Standard Deviation

$$
\sigma=\frac{\sum f i x i^{2}}{\sum f i}-(x)^{2}
$$

Students use to calculate fixi ${ }^{2}=(\text { fixi })^{2}$ that's not correct but it should be fi ${ }^{*} \mathrm{xi}^{*} \mathrm{xi}=\mathrm{fi}^{*} \mathrm{xi}^{2}$

Calculation of S. D

\begin{tabular}{|c|c|c|c|c|}
\hline Class & fi & xi & fi xi & fixi $^{2}$ \\
\hline $0-10$ & 40 & 05 & 200 & 1000 \\
\hline $10-20$ & 20 & 15 & 300 & 4500 \\
\hline
\end{tabular}

Calculation of M.D

\begin{tabular}{|c|c|c|c|c|}
\hline Class & fi & xi & fixi & $x i-x$ \\
\hline $0-20$ & 45 & & & \\
\hline $20-60$ & 30 & & & \\
\hline
\end{tabular}

Students not getting the exact concept of mod value and confused.

Use of Computers - In general the computer or computer software are not used to study or teach. But now days the different soft ware's are used. The teachers used the combination of the computer programming, PPT, different presentations of the information's of the particular subject, TV - the sports channel telecasts the live game commentary for Cricket, Football like all possible National \&International sports. One can suggest to watch the particular and understand the analysis of the commentators .So students also enjoy to watch the TV and improve their statistical knowledge, analysis of data, data samples etc. He can also make project report on that. For the BCA students can use Excel sheets, making different tables for the calculations of Measure of central Tendency- MEAN ,MODE ,MEDIAN in the colleges Department of Computers are well equipped with computer laboratories. Now a days there are practical classes for Teaching Mathematics and for Statistics practical problems are used .With the help of soft ware's like SPSS ,R Studio students can draw tables, calculations also the graphs like Histogram ,Bar charts ,two dimensional and also three dimensional to promote students active engaging and learning using the Geogebra, SageMath and Scilab to attempts long and difficult numerical and algebraic manipulations.When handling the computer students were very crazy to answering mathematical questions; to do experimental activities easier; to develop problem resolution skills dealing with more interesting. With computer software difficult problems in so far as numerical, algebraic graphical and programming resources are available; to encourage discussion on different topics like current (1) Use of helmet with two wheelers (2)Live in Metro cities.(3) Traffic problem of the area.(4)To find the pick hours of the particular road solutions or strategies, with the help of surveys and the use of Statistical tools .When answering mathematical questions; to make experimental activities easier to handle; to develop problem resolution skills dealing with more interesting and difficult problems in so far as numerical, algebraic graphical and programming resources are available; to encourage discussion of different solutions or strategies as one works with multiple representations of the same mathematical object or process. They can be used for solving problems in Calculus, Algebra, Solution of Differential Equations, Linear Programming, Statistics, plotting of points in two and three dimensions and also to create a three dimensional view of an object and many more.

On Internet available collections of activities, data sets, web applets, text materials, assessment items and a wide range of websites which present rich and motivating teaching material. The most attractive\& useful part of this section is to provide of the availability online tools for teaching statistics, highlighting some of the more common examples of each type of tool. In the next section, we present an annotated list of some of the resources, which are freelyavailable online, together with their strengths and weaknesses, audience level, content and interface design.

Example- use of Sage Mathematics software - Mathematical tool

$>$ Computer Algebra system

$>$ Numerical calculations

$>$ Symbolic Manipulations

$>$ Based on programmer language Python

$>$ Roots of Quadratic Equations

$>$ Plots graphs 2D,3D,1D

$>$ We can written our on programme

$>$-Mathematica, Metlab, Mabal

$>-64$ bits system required

$>$ May use online

$>$ Case sensitive-like small capital

$>635+543$-shift \&enter key use

$>=1178$

$>$ Multiplication with *

$>$ Division /

> Division with reminder //

$>55 \% 3$

$>$ Index 
$>$ Sqrt-square root

$>\operatorname{Sqrt}($ pi.n())

$>\operatorname{Sqrt}(2.0)=1.41421$

So like all possible arithmetic calculations and examples can solve with the help of Sagemaths.The students are very crezy about the use of computers so it helps to the faculty to use their psychology to give the easy way to solving the problem ,to develop the interest in Mathematical calculations \& Statistical methods.

To study the LPP problems students must know the particularly the English language and the proper grammar as like clause of the sentence - at the most, at least, exactly, to that point ect. Also has to dissect the given paragraphs with the help of Mathematical concepts and should be expressed in the Mathematical valid equations. To solve the equations with the different methods like Graphs - feasible solutions method and its interpretation, simultaneous, elimination of variable, substitution etc.
Group and Oral Presentation in Mathematics Learning With the help of the our Nations diversity in language the merits of oral presentations in mathematics \& Statistics gives the different types of the ideas .More types of students and many more ideas. Thus the teacher has to encourage all types of students to study basic things in Mathematics and Statistics. Every students in the classroom don't have much Mathematical brain .Therefore pedagogies must have the simple methods of formulas and the calculation parts to get much more interest in self-study and classroom learning improve and built the confidence and ability of the students in usual educational methods. Oral presentations of provide all students with a chance to display their knowledge in fun and creative ways. It provides to the teacher to here the clear and clean ideas of the students The Mathematics in their words ,justify their own opinions. The graph of the study of Mathematics is decline.

\section{Identified Problems}

\begin{tabular}{|l|l|}
\hline No & \multicolumn{1}{|c|}{ Identified Problems } \\
\hline 1 & Teaching \&learning Mathematics \& Statistics as discipline. \\
\hline 2 & Mathematics \& Statistics Phobia \\
\hline 3 & Less curiosity for learning \\
\hline 4 & Deficiencies in basic statistical knowledge \\
\hline 5 & mathematical background of students \\
\hline 6 & Statistics courses given often taught with no link to the subject area, \\
\hline 7 & Students with no mathematical background. \\
\hline 8 & $\begin{array}{l}\text { Traditional assessment techniques do not provide valid and reliable } \\
\text { measurements on important student outcomes. }\end{array}$ \\
\hline 9 & Lack of graduate programs and courses to train statistical educators. \\
\hline 10 & Less Focus on mathematical and mechanical aspects of knowledge \\
\hline 11 & Evaluating techniques Development \\
\hline 12 & Lack of expertise in the subject \\
\hline 13 & Lack of interest by the students of other discipline. \\
\hline 14 & Deficiency in use statistical tools to assess statistical thinking. \\
\hline 15 & Interpretation of the Statistical tools. \\
\hline
\end{tabular}

\section{Outcome - Probable Solutions to the Identified Problems}

\begin{tabular}{|l|l|}
\hline 1 & $\begin{array}{l}\text { Focus on mathematical and mechanical aspects of knowledge. It results in students not } \\
\text { being empowered to apply statistical content knowledge to solve problems arising from } \\
\text { a specific context. }\end{array}$ \\
\hline 2 & $\begin{array}{l}\text { Try to describe negative attitude towards statistics, pre-dispositions against statistics, } \\
\text { lack of interest displayed in students from other disciplines. }\end{array}$ \\
\hline 3 & Try to improve the interest in learning both the subjects for employment. \\
\hline 4 & Give the current examples. \\
\hline 5 & Has to brush-up the basic statistical \& Mathematical knowledge \\
\hline 6 & $\begin{array}{l}\text { Has to service teaching are taught with link to the subject area\& by subject-specific } \\
\text { specialists who are statisticians. }\end{array}$ \\
\hline 7 & Try to improve the Mathematical \& Statistical background of the students in person. \\
\hline 8 & $\begin{array}{l}\text { Traditional assessment techniques do not provide valid and reliable measurements on } \\
\text { important student outcomes such as statistical reasoning. }\end{array}$ \\
\hline 9 & The FDP programs must arrange for the faculties. \\
\hline 10 & Find more and more current examples and the employability resources for the students. \\
\hline 11 & $\begin{array}{l}\text { Evaluating innovations in education Rigorous evaluation of innovation in higher } \\
\text { education is key to its sustainability and success. It is crucial that when universities } \\
\text { transform their teaching, they also study the effectiveness of their methods and share } \\
\text { the outcomes of this evaluation with colleagues internally and externally. }\end{array}$ \\
\hline 12 & FDP programs for the faculty members \\
\hline 13 & Give the confidence to the students for the best teaching. \\
\hline 14 & Practice \& difficulty sessions must arrange for the students. \\
\hline 15 & FDP, practice computer laboratory sessions must arrange. \\
\hline
\end{tabular}

Outcomes - 
International Journal of Trend in Scientific Research and Development (IJTSRD) @ www.ijtsrd.com eISSN: 2456-6470

References

[1] UGC model curriculum statistics 2001

[2] Venkataraman, G et al,. (2012). Curriculum and pedagogy in mathematics: Focus on the tertiary level, Proceedings of the Indian national presentation on mathematical education 2012.

[3] Workshop at MIT.

\begin{tabular}{|c|c|c|c|c|c|c|c|c|c|c|c|c|c|c|}
\hline \multirow[t]{2}{*}{$\overline{\text { Age }}$} & \multicolumn{2}{|c|}{ No. of Students } & \multicolumn{2}{|c|}{ Domain } & \multicolumn{2}{|c|}{ Height } & \multicolumn{2}{|c|}{ Weight } & \multicolumn{2}{|c|}{$\begin{array}{l}\text { Training } \\
\text { Yrs }\end{array}$} & \multicolumn{2}{|c|}{$\begin{array}{l}\text { Pre- intervention } \\
\text { speed }\end{array}$} & \multicolumn{2}{|c|}{$\begin{array}{c}\text { Post- intervention } \\
\text { speed }\end{array}$} \\
\hline & M & $\mathrm{F}$ & M & $\mathrm{F}$ & M & $\mathrm{F}$ & M & $\mathrm{F}$ & M & $\mathrm{F}$ & M & $\mathrm{F}$ & M & $\mathrm{F}$ \\
\hline 12 & 0 & 1 & Right & Right & NA & 163 & & 53 & & 7 & & 132 & & 134 \\
\hline 13 & 3 & 13 & Right & Right & 171.3 & & 58 & & & & & & 131.1 & 127 \\
\hline 14 & 4 & 6 & Right & Right & 178 & 164 & 61 & 50 & 7.13 & 6 & 156 & 124.38 & 160 & 129 \\
\hline 15 & 2 & 1 & Right & Right & 177 & 168 & 63 & 52 & 9 & 8 & 154 & 139.24 & 157.44 & 144 \\
\hline \multicolumn{15}{|c|}{ Test used - Stdent's t test $\quad$ S.D. $=0.135$} \\
\hline \multicolumn{15}{|c|}{$\mathrm{t}($ table $)=20.045$} \\
\hline
\end{tabular}

